\title{
Canines on a Fast Track: Canine Distalization by Dento- alveolar Distraction Osteogenesis
}

\author{
Bhavna Virang, Anup Belludi, Amit Bhardwaj, Sagar Padmawar, Parag Virang
}

\begin{abstract}
Conventional techniques for biological tooth movement is routinely achieved at a slow rate and in high anchorage cases where individual canine retraction is indicated lasts for 6 to 8 months, followed by retraction of the incisors. Hence, the overall treatment time taken is about 18 to 24 months. Rapid canine distalization through dentoalveolar distraction (DAD) technique can be achieved within 2 to 3 weeks with this technique. This clinically efficient method significantly reduces the overall treatment time without causing any serious discomfort or damage to the patient. In this technique osteotomies surrounding the canines are made to achieve rapid movement of the canines within the dentoalveolar segment, in compliance with distraction osteogenesis principles.
\end{abstract}

Keywords: Canine distalization, Distraction osteogenesis, Tooth movement, Anchorage.

How to cite this article: Virang $B$, Belludi $A$, Bhardwaj $A$, Padmawar S, Virang P. Canines on a Fast Track: Canine Distalization by Dentoalveolar Distraction Osteogenesis. Int J Experiment Dent S ci 2013;2(1):44-49.

Source of support $\mathrm{Nil}$

Conflict of interest: None declared

\section{INTRODUCTION}

Distraction osteogenesis is a process whereby new bone is grown by mechanically stretching a pre-existing bone tissue. It was made popular in studies by Ilizarov ${ }^{1}$ who showed in hundreds of patients that new bone could be formed after surgical corticotomy followed by distraction osteogenesis. The first phase of treatment in premolar extraction cases is distal movement of the canines. Biological tooth movement with conventional techniques is limited. ${ }^{2,3}$ The retraction phase of the canine tooth into an extraction site usually lasts about 6 to 8 months, and under normal circumstances, conventional treatment with fixed appliances is likely to last about 20 to 24 months. In addition, retraction of the canines enhances the need for using extraoral or intraoral anchorage appliances when maximum or moderate anchorage is required. In 1959, K ole ${ }^{4}$ presented a technique that combined orthodontics with 'corticotomy' surgery to increase the rate of tooth movement. In 1998, Liou and Huang ${ }^{5}$ introduced the technique of distraction of the periodontal ligament for rapid tooth movement. In 2001, I seri and K isnisci ${ }^{6-9}$ introduced a new technique named dentoalveolar distraction (DAD), which achieves rapid tooth movement using the principles of distraction osteogenesis.
In the present high anchorage case the upper canines were distracted over a period of 11 days using a tooth supported dentoal veolar canine distractor made of stainless steel.

\section{DISTRACTOR APPLIANCE DESIGN}

The preformed canine distractor is a tooth-borne, semirigid device made up of stainless steel, manufactured by SK Surgical (Figs 1 and 2). A fter the bands were selected for the canines and first molars, an impression was obtained, the bands were transferred into the impression material, and the study cast was made. The distraction device consisted of a conventional hyrax screw and canine and first molar bands soldered on the arms of the screw (Figs 3 and 4).

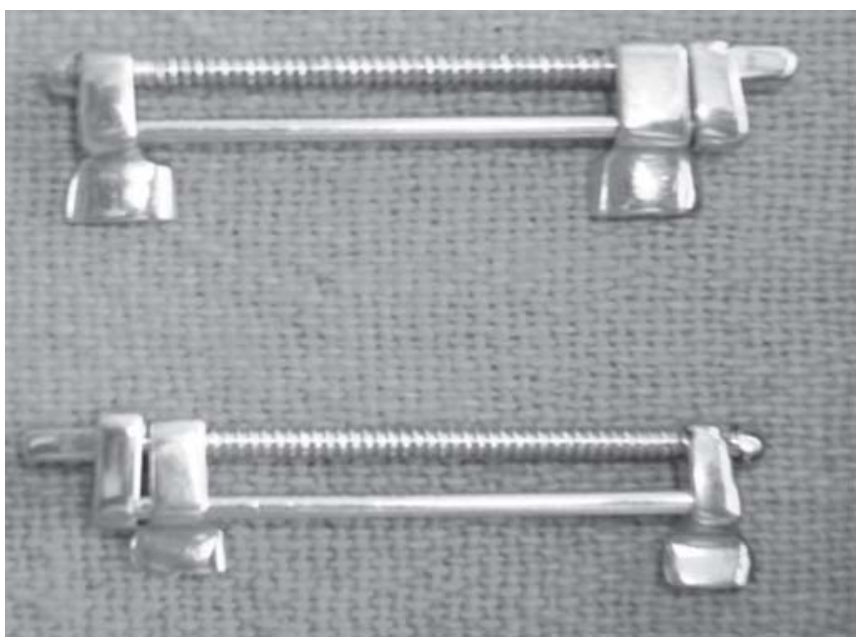

Fig. 1: Distractor appliance

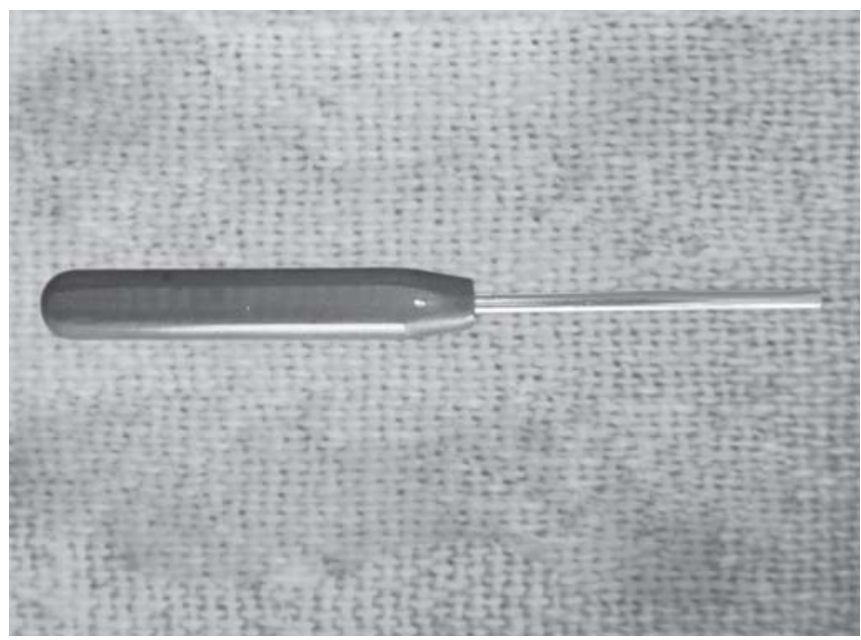

Fig. 2: Distractor activator 


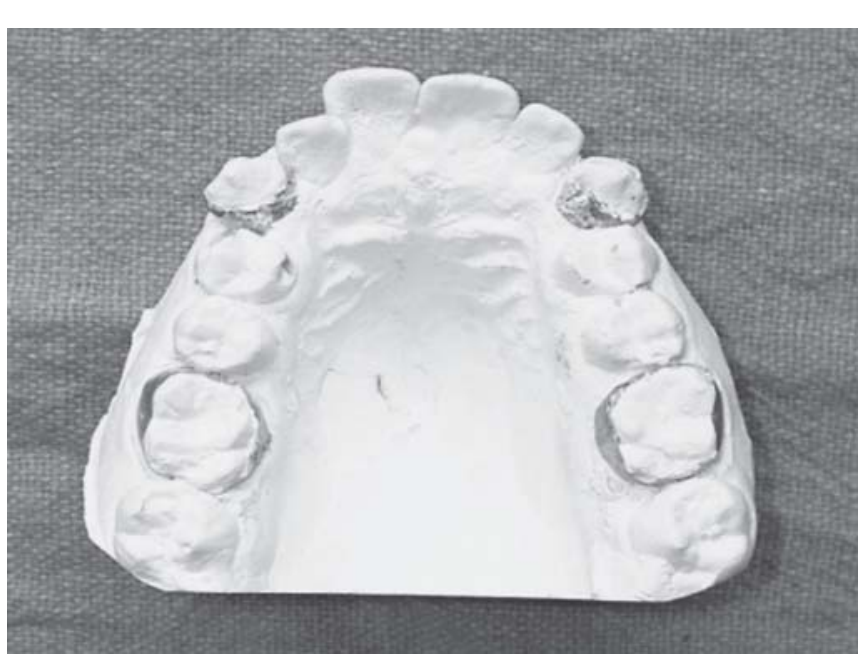

Fig. 3: Banding of canines and molars

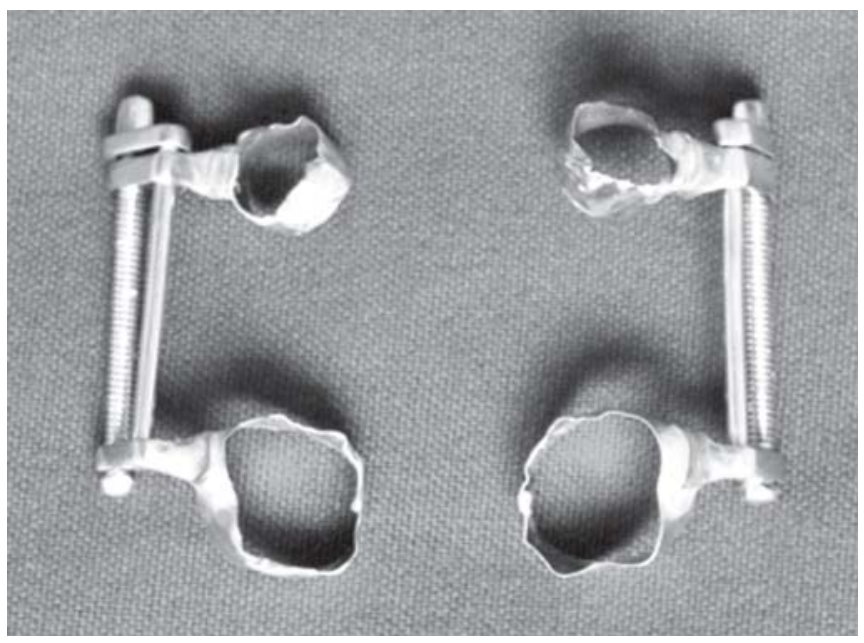

Fig. 4: Soldering of bands to distractor

The device consists of an anterior section, a posterior section, a screw, and a hex wrench to advance the screw. The posterior section included a round sliding rod, a retention arm (with a rectangular tip) for the first molar tube, and a grooved screw socket. The anterior section included a retention arm (with rectangular tip) for the canine tube and two nongrooved slots for the sliding rod and screw. The top of the screw was designed thicker than the grooved part and was of a rectangular shape to facilitate patient activation of the screw with a distractor activator.

\section{Surgical Method}

A horizontal mucosal incision was made parallel to the gingival margin of the canine and premolar beyond the depth of the vestibule ${ }^{10}$ (Figs 5 and 6). Multiple cortical holes were made on the alveolar bone with a small, round, carbide bur on the medial aspect of the tooth to be distracted. The same procedure was applied on the distal aspect of the canine close to the extraction area, and the holes around the canine root were connected using a thin, tapered fissure bur. The

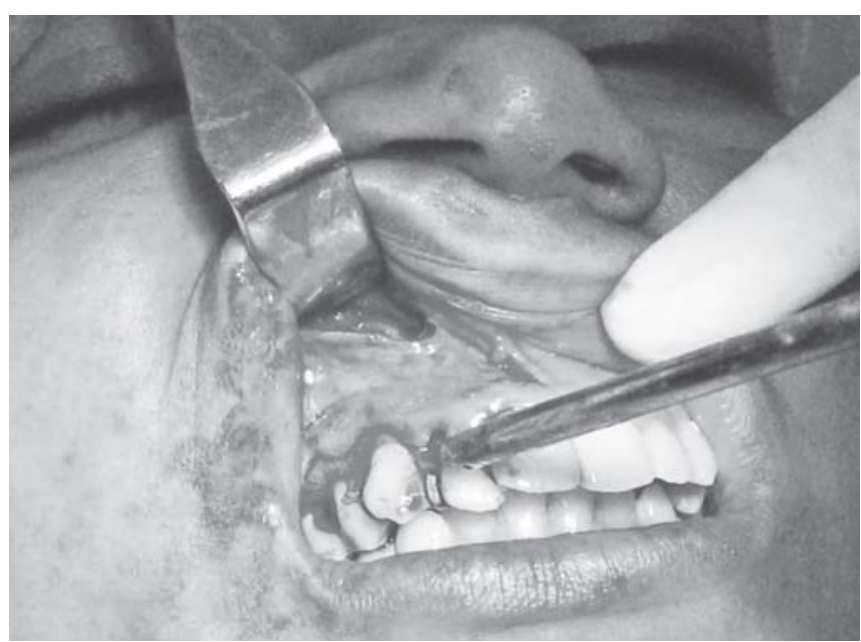

Fig. 5: Incision given

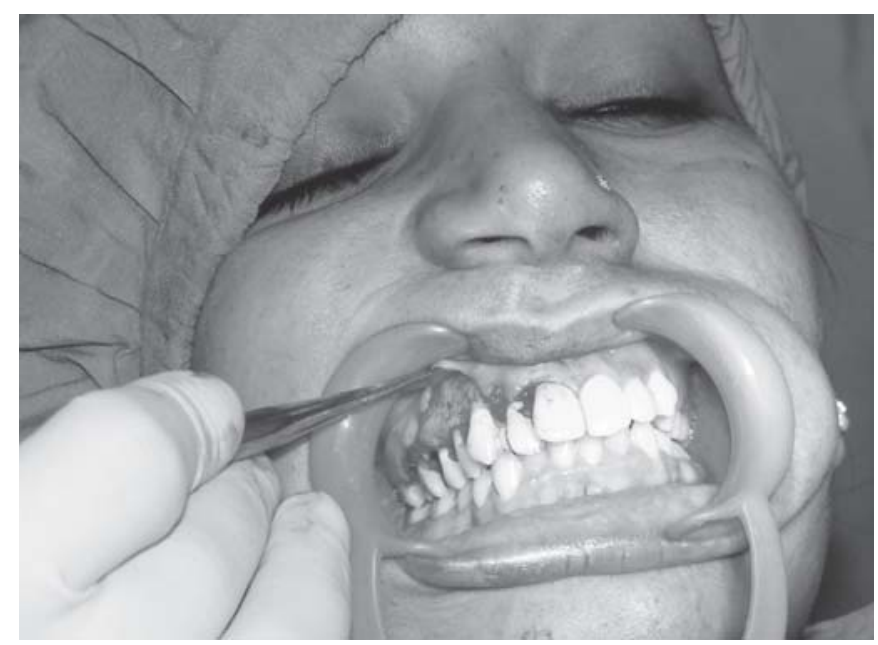

Fig. 6: Flap raised

osteotomy curved apically at a distance of 3 to $5 \mathrm{~mm}$ from the apex. Then, the osteotomes were advanced in the coronal direction. At this stage, the first premolar was extracted (Figs 7 and 8) and the buccal bone removed (Fig. 9) between the outlined bone cut at the distal canine region anteriorly and the second premolar posteriorly using a round bur. The palatal shelf was preserved, but the apical bone near the sinus wall was removed (Fig. 10), leaving the sinus membrane intact to avoid interference during the distraction process. O steotomes were used along the anterior aspect of the canine to split the surrounding bone around its root from the palatal or lingual cortex and neighboring teeth. The transport dentoalveolar segment that included the canine also included the buccal cortex and the underlying spongy bone that enveloped the canine root, leaving an intact lingual or pal atal cortical plate and the bone around the apex of the canine after these sutures were given (Figs 11 to 14). Finally, the distractor was cemented onto the canine and the first molar (Fig. 15). To ensure that the transport segment was fully mobilized, the alveolar segment carrying the canine 


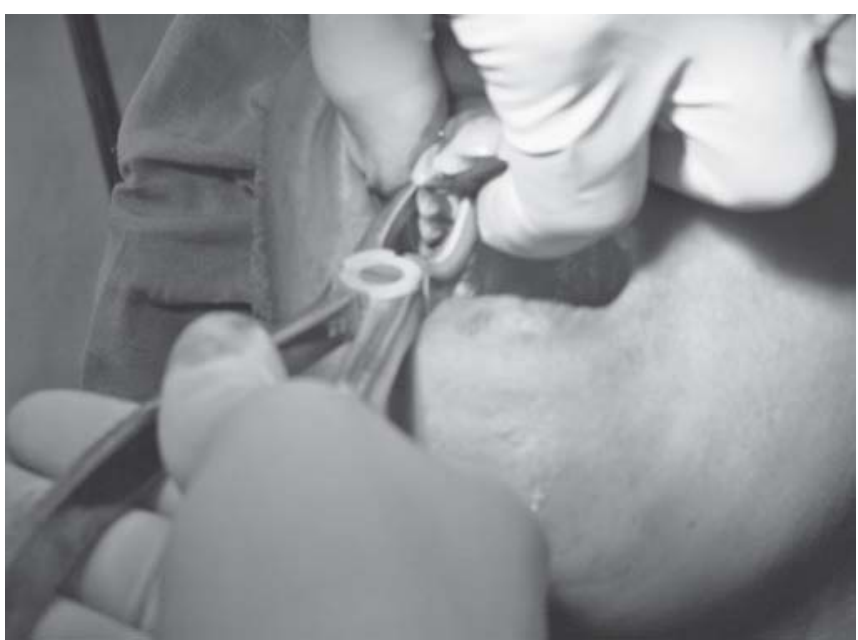

Fig. 7: First premolar extraction

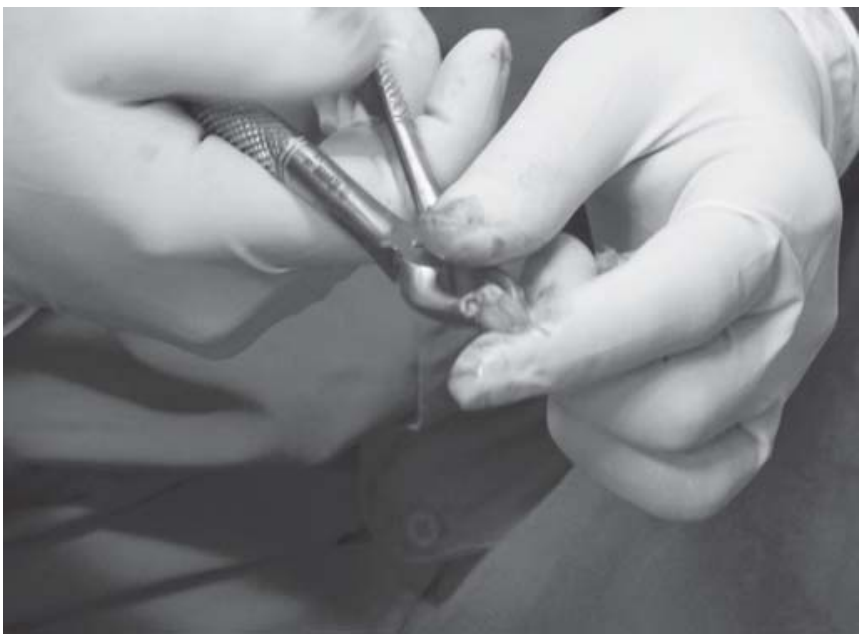

Fig. 8: Extraction done

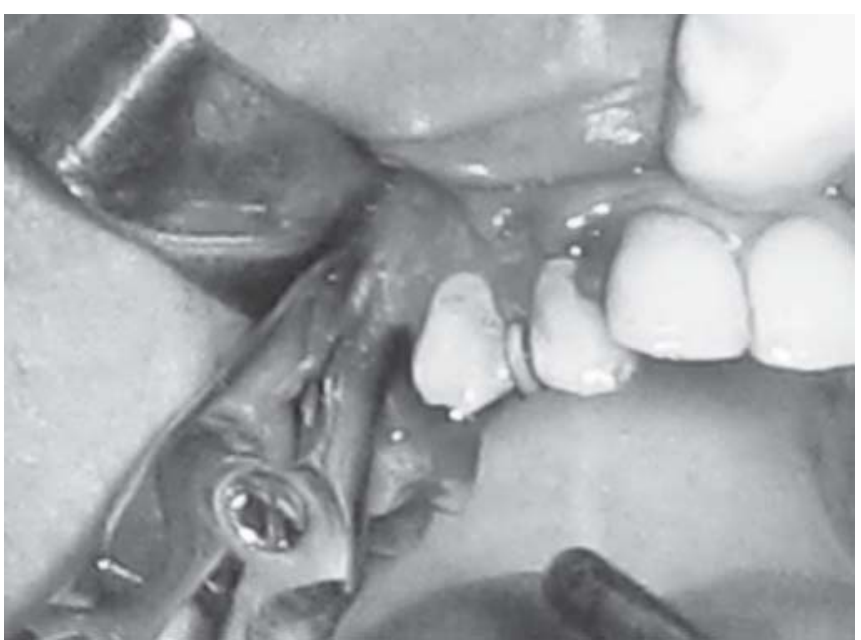

Fig. 9: Removal of buccal cortical plate

was mobilized intraoperatively by activating the device several millimeters and setting it back to its original position. The incision was closed with absorbable sutures, and an antibiotic and nonsteroidal anti-inflammatory drug were prescribed for 5 days. The surgical procedure usually lasted

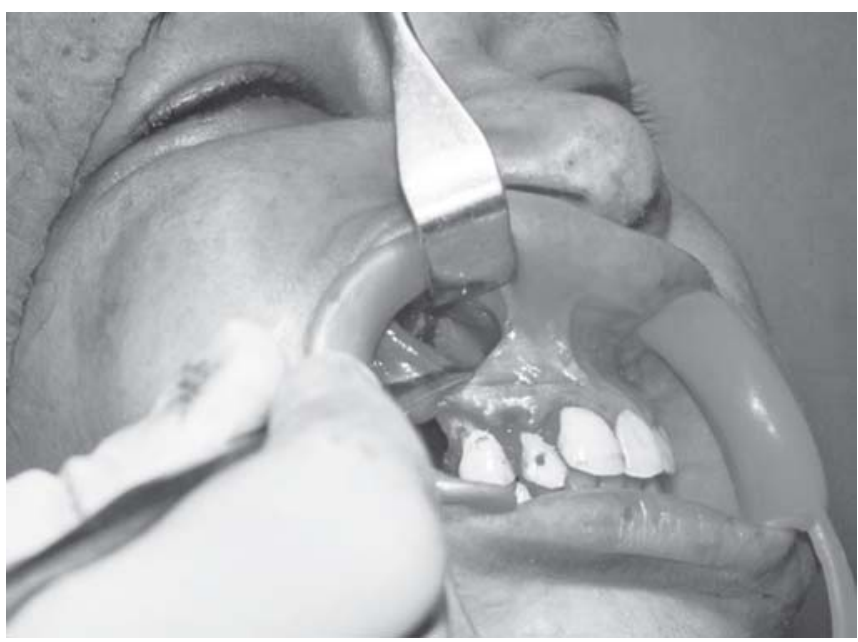

Fig. 10: Apical osteotomy cut

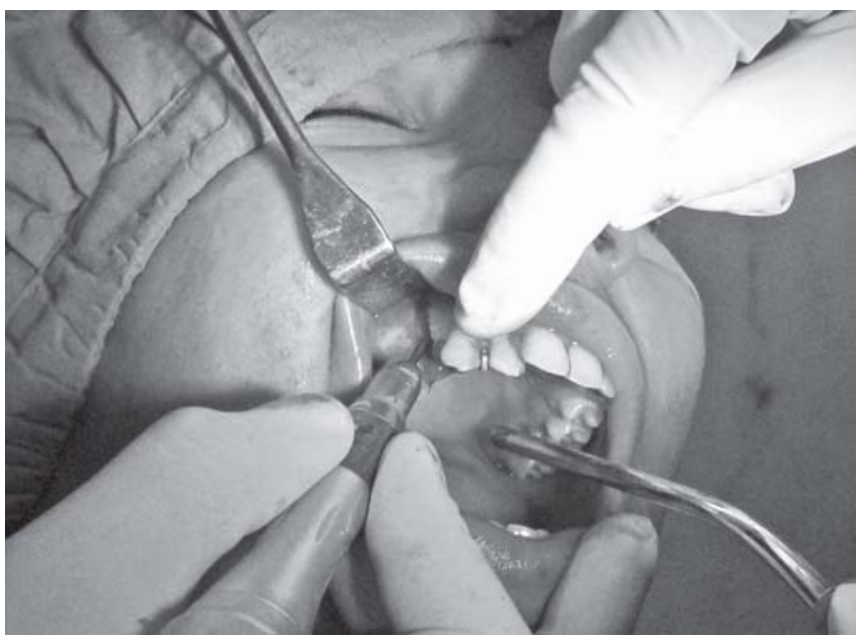

Fig. 11: Increasing premolar socket depth

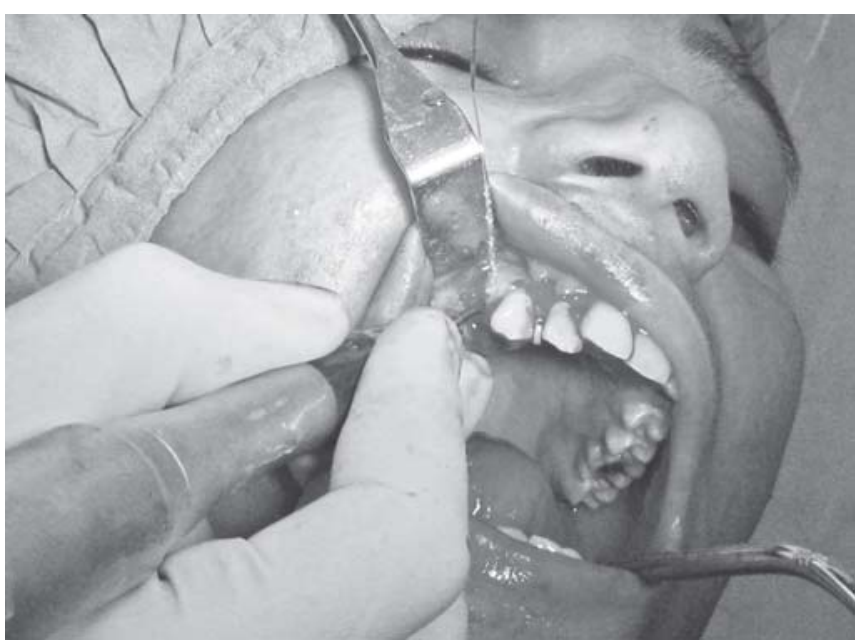

Fig. 12: Reduction of interseptal bone

about 30 minutes for each tooth. ${ }^{7,8}$ The patient was instructed to discontinue tooth brushing for 3 days to avoid trauma around the surgical site. A $0.2 \%$ chlorhexidine gluconate rinse was prescribed twice a day during the distraction period. ${ }^{7}$ 


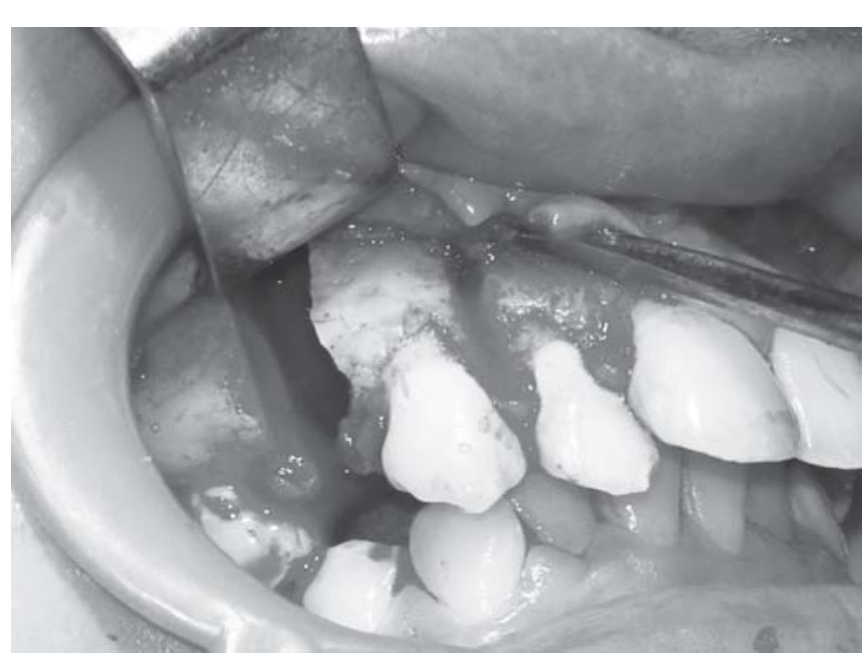

Fig. 13: Osteotomy cuts

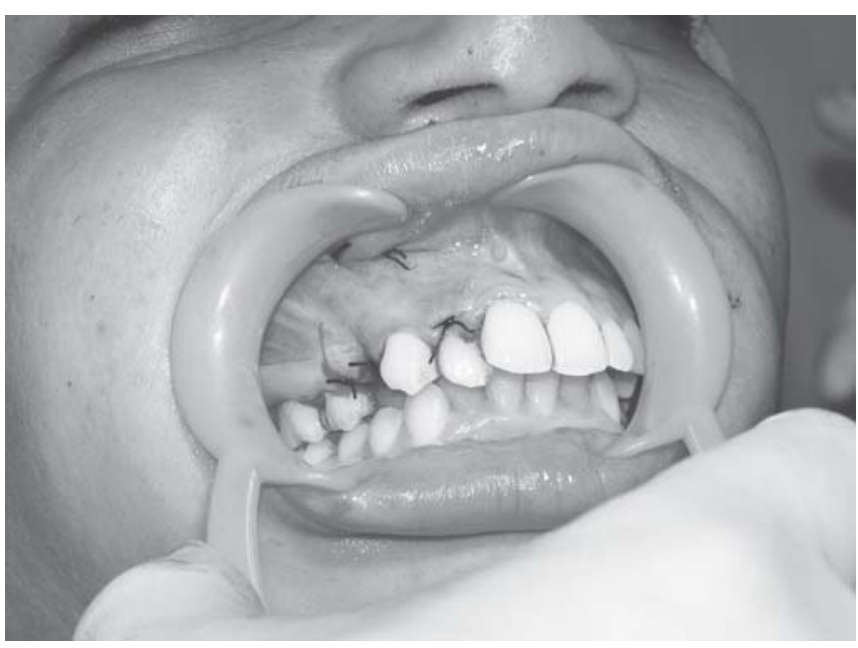

Fig. 14: Sutures given

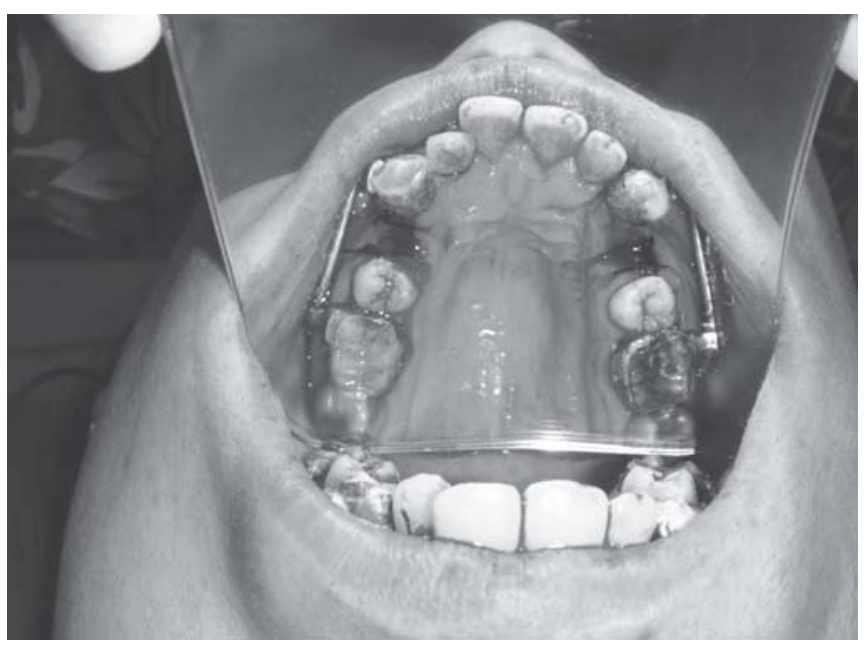

Fig. 15: Immediate cementation of appliance

\section{Distraction Protocol}

The device was activated right after surgery $(0.5 \mathrm{~mm})$ twice a day until each canine tooth was distracted into the desired position (Fig. 16). The patients were closely monitored during the distraction period, and a class I canine relationship was attained after an average of 2 weeks (Figs 17 to 19). A fter a 2-week consolidation period, the distractors were removed and retraction of incisors was started. Intraoral photographs and radiographs (IOPA ) of a patient before and after rapid canine distalization were taken (Figs 20 and 21).

\section{Treatment Progress}

The distractor was continued for 12 days, and then the leveling phase was immediately initiated by $0.014-$ or 0.016 inch nickel-titanium archwires in the upper and lower dental arches. Next appointment, retraction of the maxillary anterior teeth was started.

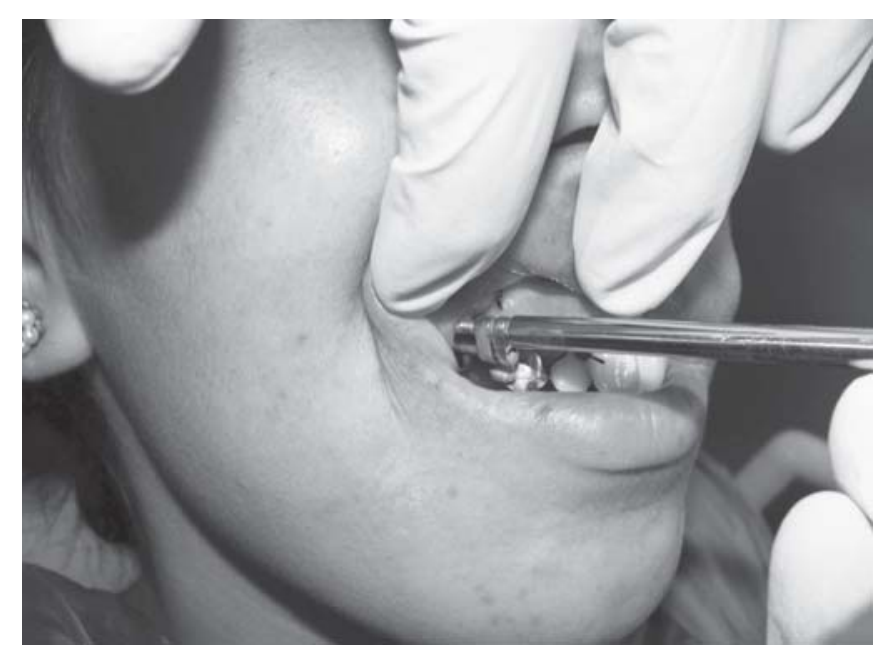

Fig. 16: $180^{\circ}$ activation done

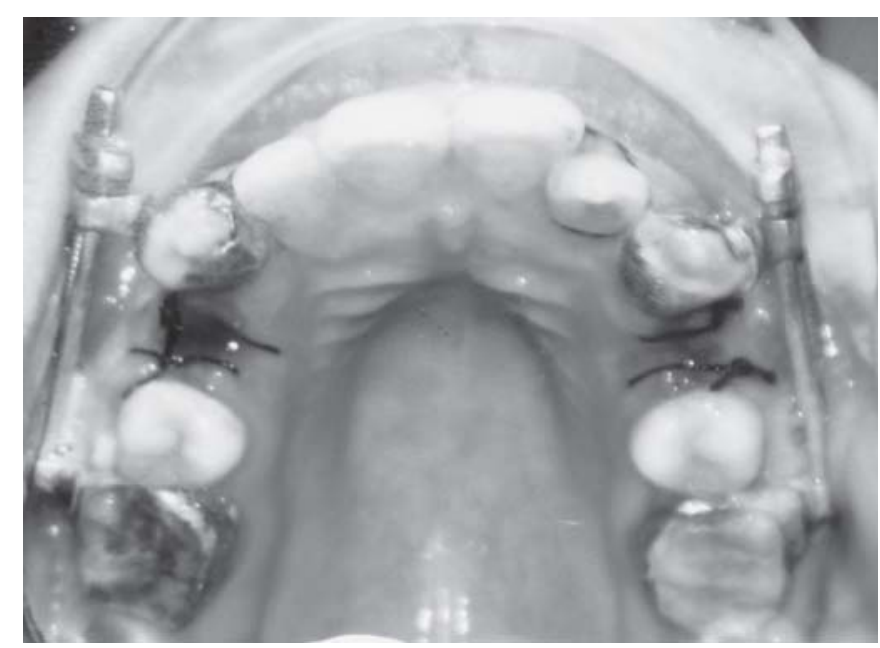

Fig. 17: After 2 days of activation

\section{Pulp Vitality}

- Clinically, no color changes were observed.

- No positive findings were reported with electronic pulp tester. 


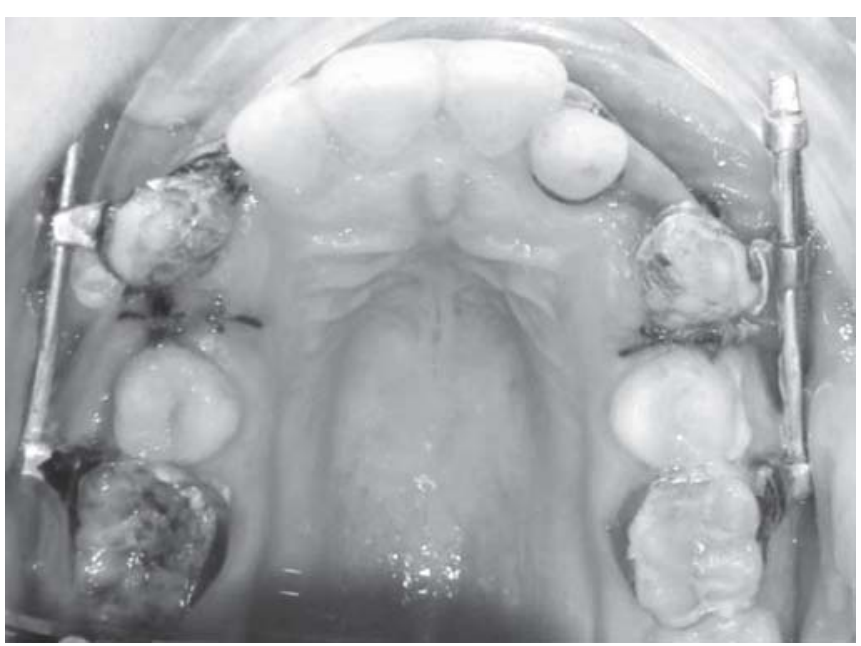

Fig. 18: After 7 days of activation

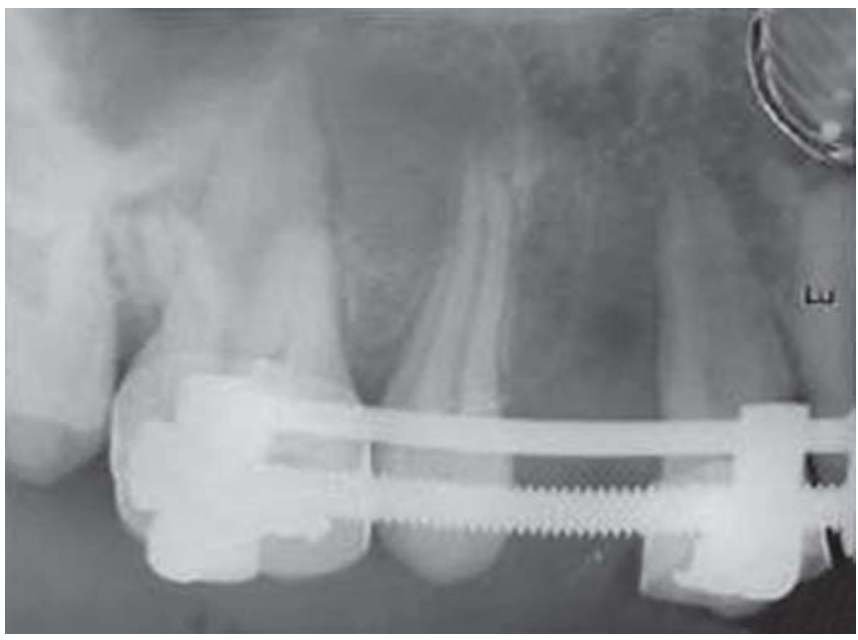

Fig. 20: IOPAR immediately after placing distractor appliance
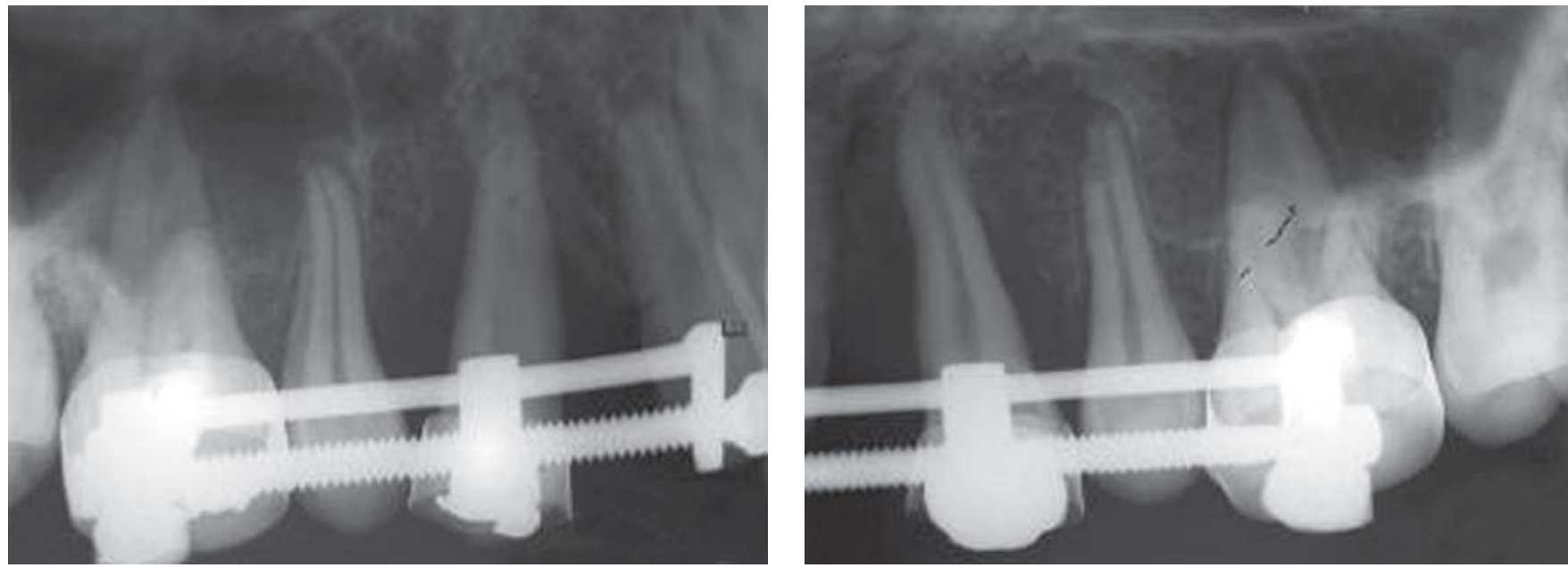

Fig. 21: IOPAR after 11 days of activating distractor appliance

\section{Advantages}

- Rapid retraction of the canine.

- Minimal loss of anchorage in capital and vertical direction.

- Elimination of need of additional anchorage support.

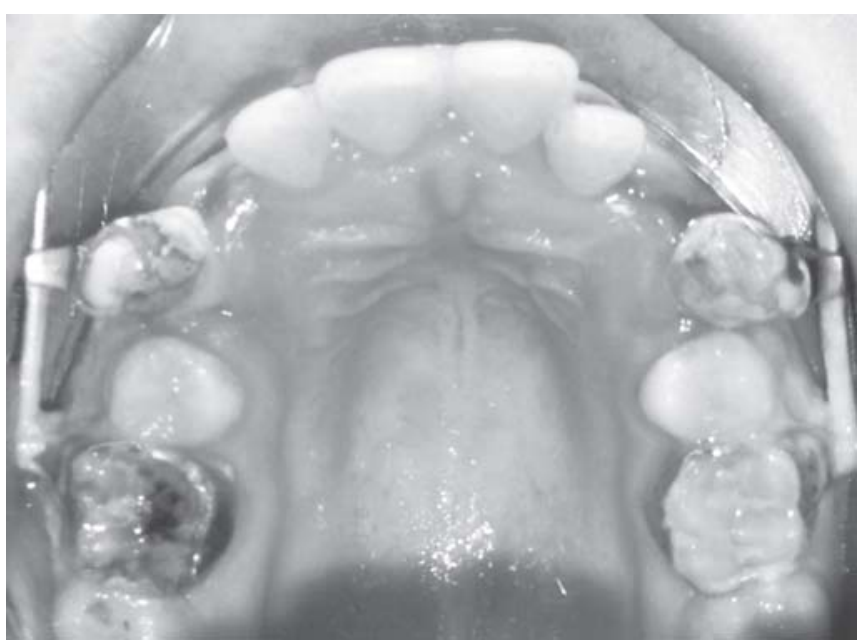

Fig. 19: After 11 days of activation

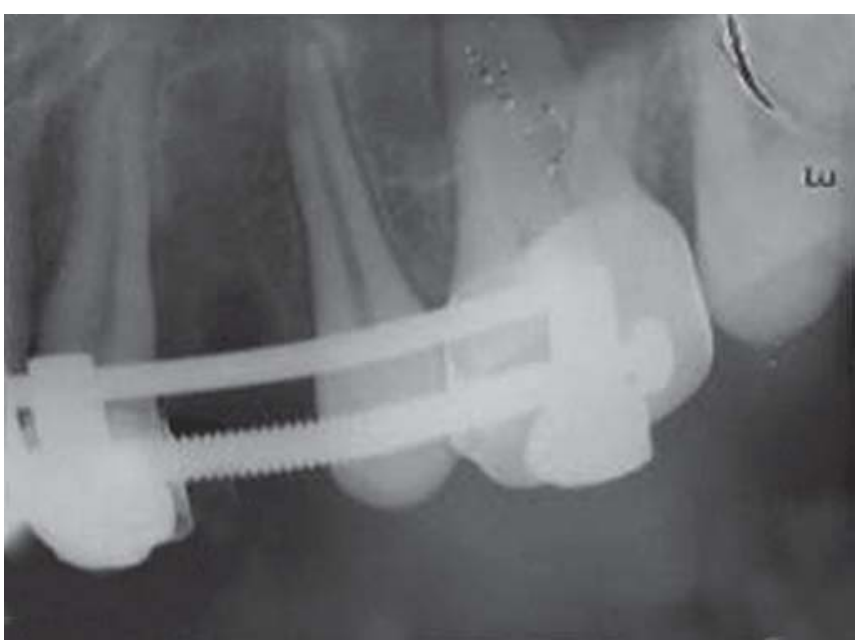

$\omega$

\section{CONCLUSION}

- Canine distraction is primarily indicated in adults presenting bimaxillary protrusion, a class II division 1 malocclusion with maxillary dentoalveolar excess or anterior crowding. When maximum anchorage is 
required, it can also be used in the treatment of adolescent patients with anterior crowding.

- Canine distalization with dentoalveolar distraction minimizes treatment time, and both the upper and lower canines can be distalized successfully within 3 weeks with controlled distal tipping. Incisor retraction can al so be facilitated with this technique because the bone distal to the lateral incisors is still fibrous.

- Overall treatment time can be reduced significantly.

\section{REFERENCES}

1. Ilizarov GA. Clinical application of the tension-stress effect for limb lengthening. Clin Orthop R elat Res 1989 J an;250:8-26.

2. Reitan K. Clinical and histological observations on tooth movement during and after orthodontic treatment. A m J Orthod Dentofac Orthop 1967;53:721-45.

3. Rygh P. Elimination of hyal inized periodontal tissues associated with orthodontic tooth movement. Scand J Dent Res 1974;80: 57-73.

4. Kole H. Surgical operations on the alveolar ridge to correct occlusal abnormalities. Oral Surg Oral Med Oral Pathol Oral Radiol Endod 1959;12:515-29.

5. Liou EJW, Huang CS. Rapid canine retraction through distraction of the periodontal ligament. A m J Orthod Dentofac Orthop 1998;114:372-82.

6. Iseri H, Bzeizi N, Kisnisci R. Rapid canine retraction using dentoalveolar distraction osteogenesis [abstract]. Eur J Orthod 2001;23:453.

7. Kisnisci R, Iseri $H, T$ Tuz $H$, A Itug A. Dentoalveolar distraction osteogenesis for rapid orthodontic canine retraction. J Oral M axillofac Surg 2002;60:389-94.
8. I seri H, Kisnisci R, Bzizi N, Tuz H. Rapid canine retraction and orthodontic treatment with dentoalveolar distraction osteogenesis. A m J Orthod Dentofac Orthop 2005;127:533-41.

9. Gurgan CA, Iseri H, Kisnisci R. Alterations in gingival dimensions following rapid canine retraction using dentoalveolar distraction osteogenesis. Eur J Orthod 2005;27:324-32.

10. Kurta G, Iserib H, Kisnisci R. Rapid tooth movement and orthodontic treatment using dentoalveolar distraction (DAD). A ngle Orthod 2010;80:597-606.

\section{ABOUT THE AUTHORS}

\section{Bhavna Virang (Corresponding Author)}

Senior Lecturer, Department of Orthodontics and Dentofacial Orthopedics, M odern Dental College and Research Centre, Indore M adhya Pradesh, India, e-mail: bhavnamds@gmail.com

\section{Anup Belludi}

Professor, Department of Orthodontics, KLE Dental College and Hospital, B engaluru, Karnataka, India

\section{Amit Bhardwaj}

Professor, Department of Orthodontics, M odern Dental College and Research Centre, Indore, M adhya Pradesh, India

\section{Sagar Padmawar}

Senior L ecturer, Department of Orthodontics, Index I nstitute of Dental Sciences, Indore, Madhya Pradesh, India

\section{Parag Virang}

Senior L ecturer, Department of O ral Surgery, M odern D ental College and Research Centre, Indore, M adhya Pradesh, India 